\title{
ESPÉCIE NOVA DE ISCHNOPTERA BURMEISTER, 1838 \\ (BLATTARIA: BLATTELLIDAE: BLATTELLINAE) DO ESTADO DE GOIÁS, BRASIL, COLETADA EM NINHO DE CUPIM.
}

\author{
Sonia Maria Lopes ${ }^{I} \&$ Edivar Heeren de Oliveira ${ }^{I}$
}

Biota Neotropica v5 (n1) - http://www.biotaneotropica.org.br/v5n1/pt/abstract?article+BN02405012005

\author{
Recebido: 04/10/2004 \\ Revisado: 21/11/2004 \\ Publicado: 01/01/2005
}

1.Museu Nacional, Universidade Federal do Rio de Janeiro, Departamento de Entomologia, Quinta da Boa Vista, São

Cristóvão, 20940-040 Rio de Janeiro, RJ, Brasil. Endereço eletrônico: sonialf@acd.ufrj.br

\begin{abstract}
Ischnoptera bicolorata sp. nov. is described based on a single specimen collected in a termite's nestt. Illustrations of the male genitalia and the coments about the etology of this species are provided.
\end{abstract}

Key words: Ischnoptera bicolorata sp. nov, Blattaria, termite's nest.

\section{Resumo}

Ischnoptera bicolorata sp. nov. coletada em ninho de cupim (Isoptera) é descrita neste trabalho com base em um único exemplar. As ilustrações da genitália masculina e comentários sobre o comportamento da espécie são apresentados.

Palavras-chave: Ischnoptera bicolorata sp. nov, Blattaria, ninho de cupim. 


\section{Introdução}

O gênero Ischnoptera foi descrito por Burmeister (1838) que designou para espécie-tipo Ischnoptera morio, designada por KIRBY (1904)

O gênero apresenta grande diversidade sendo até o momento conhecidas na literatura 51 espécies que se encontram distribuídas em países da América Latina e América Central. No Brasil já foram registradas 39 espécies e na região centro-oeste há registro de duas (I. brunnea R.S.-Albuquerque, 1964 e I. bilunata Saussure, 1869) para Mato Grosso.

Neste trabalho assinalamos, pela primeira vez a presença de I. rehni Hebard, 1916 em Goiás e de I. bicolorata sp. nov que aqui descrevemos.

Foi a espécie coletada em ninho de cupins, em uma área de campo limpo, no Parque Nacional das Emas, no Estado de Goiás. Tais cupins (Conitermes cumulans (Kollar, 1832)), pertencem à família Termitidae, cujos indivíduos constróem seus ninhos em forma de montículos cônicos sobre a superfície do solo. As ilustrações da genitália do macho e comentários sobre o local de coleta da espécie são apresentados.

Considerações sobre o gênero foram até o momento feitos por BURMEISTER (1838), FINOT (1897), BRUIJNING (1959), VANSCHUYEBROECK(1970)eFISK\&WOLDA(1979).

\section{Material e Métodos}

A coleta do material foi feita por Rodrigo Assis de Carvalho, Guilherme Ferreira de Lima Filho e Diogo Andrade Costa dentro do Projeto Dinâmica Biológica de Fragmentos Florestais (PDBFF). A observação das placas genitais foi feita através da retirada da parte final do abdome do exemplar macho, utilizando-se técnicas tradicionais para dissecção, após a imersão da parte final do abdome, por cerca de 24 horas, em solução de hidróxido de potássio $(10 \%)$ a frio. A seguir, lavadas em água destilada e desidratadas por 5 minutos, em série alcoólica. As dissecções das placas genitais para exame em lâmina foram feitas imersas em glicerina, com auxílio de estiletes apropriados.

A designação das peças genitais e a classificação taxonômica foram baseados nos conceitos propostos por MCKITTRICK (1964).

Após análise, as placas e peças genitais foram guardadas em "microvial" contendo glicerina e devidamente acondicionadas junto ao exemplar respectivo, montado em alfinete entomológico na coleção, técnica desenvolvida por GURNEY, KRAMER \& STEYSKAL (1964).

\section{Resultados}

Ischnoptera bicolorata sp. nov.

MATERIAL EXAMINADO: Holótipo macho. Brasil,
Goiás, Município de Mineiros, Parque das Emas, 18³2’42”S, $53^{\circ} 07^{\prime} 40^{\prime \prime} \mathrm{W}$ (coletado em cupinzeiro, ninho 143), Rodrigo Assis de Carvalho, Guilherme Ferreira de Lima-Filho \& Diogo Andrade Costa, cols, 16/04/2004 (MNRJ).

Coloração Geral - castanho-escuro. Pronoto (Fig. 2), cabeça (Fig. 1), palpos, coxas da base até a região mediana, negros, levemente fosco. Ocelos pardos. Palpos e artículos tarsais com tomentosidade dourada. Tégminas bicoloridas, com campo marginal castanho-avermelhado, campo discoidal castanho-acinzentado, com nervuras transversais bem marcadas. Asas castanho-claras e transparentes, com campo marginal mais pigmentado e ápices dos campos escapular e discoidal acinzentado. Pernas com as coxas da região mediana para o ápice e fêmures amarelo-esbranquiçados. Unhas castanhas.

Cabeça - Pequena, vértice levemente exposto sob o pronoto, Olhos pequenos, espaço interocular amplo, pouco maior que a área que separa a base das inserções antenais, fronte estreita e saliente, ocelos desenvolvidos, antenas longas, ultrapassando o ápice do abdome, tomentosas e filiformes; palpos maxilares desenvolvidos, sendo o terceiro e o quinto artículos com comprimento igual ao espaço interocular, e o quarto segmento menor que os citados anteriormente.

Tórax - Pronoto trapezoidal, de ápice reto, faces laterais levemente arredondadas e base suavemente angular, delineando-se dois sulcos divergentes, bem marcados, partindo da base em direção às laterais (Fig. 2). Tégminas longas, ultrapassando em comprimento o ápice dos cercos, sendo a área mais larga e ampla próximo ao ápice; campo marginal côncavo e bem marcado; campo escapular estreito e oblíquo; campo discoidal amplo e longitudinal, e campo anal relativamente curto. Asas desenvolvidas, campo anterior estreito, alongado, com ramos da radial oblíquos e não dilatados apicalmente; triângulo apical não desenvolvido e campo posterior amplo e dobrado em leque. Pernas alongadas, desenvolvidas e bastante tomentosas. Fêmur I com cinco espinhos grandes e espaçados, semelhantes em tamanho até a região mediana, seguidos por uma série de quinze espinhos menores até próximo ao ápice, apresentando um pré-apical desenvolvido e dois apicais maiores; face póstero-ventral com três espinhos fortes, sendo um mediano, um no terço apical e um apical. Fêmures II e III com espinhos grandes e espaçados, semelhantes nas faces ântero e póstero-ventrais; pulvilos presentes em todos os artículos das pernas e arólio pouco desenvolvido. Unhas longas, simétricas e sem especialização.

Abdome - Modificação tergal no sétimo segmento típica do gênero, em forma de pente centralizado. Placa supra-anal intensamente ciliada, projetada entre os cercos e ligeiramente invaginada medianamente. Cercos pilosos, afilando para o ápice (Fig. 4). Placa subgenital alargada, ciliada e assimétrica, com pequena proeminência entre os estilos, os quais são assimétricos de tamanhos e forma 


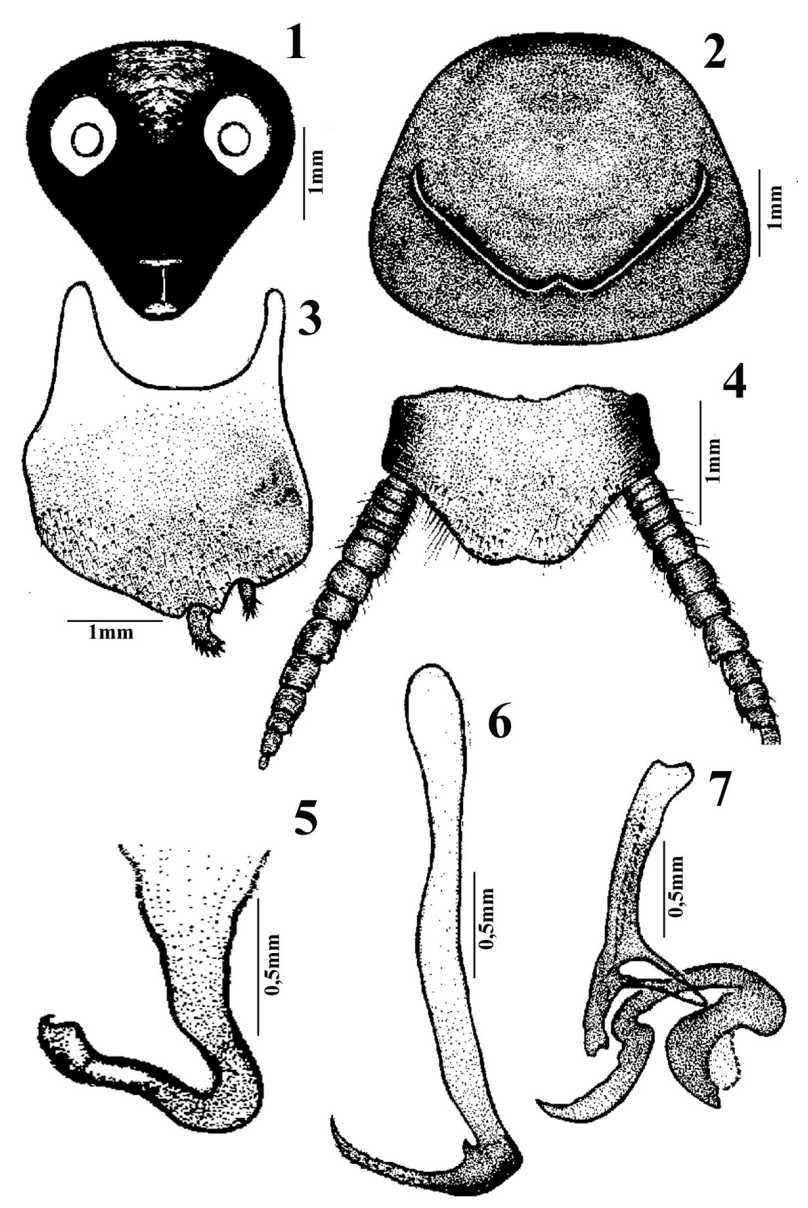

Figuras 1-7. Ischnoptera bicolorata sp. nov. Holótipo macho. 1. Cabeça. 2. Pronoto. 3. Placa subgenital. 4. Placa supra-anal. 5. Falomero esquerdo (L3). 6. Esclerito mediano (L2vm). 7. Falômero direito (R2).

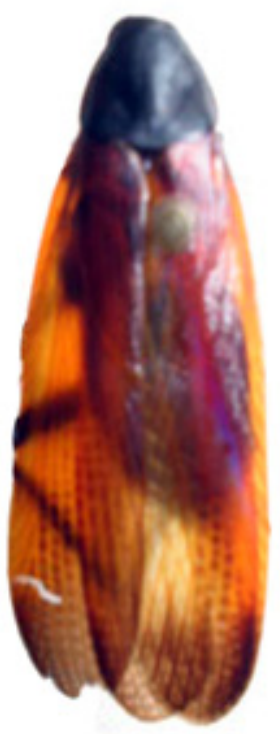

Figuras 8. Ischnoptera bicolorata sp. nov. Holótipo macho 
diferentes, pequenos, alargados e ciliados em seu contorno e localizados na região látero-apical da placa (Fig. 3). Falômero direito (R2) com a haste mediana em forma de Y e duas projeções esclerotizadas sem forma definida (Fig. 7). Falômero esquerdo (L3) em forma de gancho afilado, com o ápice sinuoso e muito desenvolvido (Fig. 5). Esclerito mediano (L2vm) afilado com o ápice (L2d) em forma de uma foice muito desenvolvida (Fig. 6).

Dimensões (em mm): Holótipo macho. Comprimento total: 20,0; comprimento do pronoto: 3,5 ; largura do pronoto: 4,5; comprimento da tégmina: 17,0; largura da tégmina: 5,0.

Etimologia: O nome da espécie deve-se a coloração do exemplar.

Ischnoptera bicolorata sp. nov. distingue-se das demais espécies do gênero pela coloração do pronoto e tégminas e a configuração da genitália masculina.

\section{Discussão}

Neste trabalho o gênero Ischnoptera é assinalado, pela primeira vez, em cupinzeiro, já tendo sido notificado, associado a formigas e ninhos de pássaros, não havendo explicação mais definida para essa associação (RоTн \& WILLIS, 1960).

\section{Agradecimentos}

À Dra. Janira Martins Costa (MNRJ) pelo apoio técnico. À Rodrigo Assis Carvalho pela coleta do material.

\section{Referências Bibliográficas}

BURMEISTER, H., 1838. Blattina, In: Handbuch der Entomologie, Berlin: I.C.F. Enslin 2(2):469-517.

BRUIJNING, C. F. A., 1959. The Blattidae of Surinam. Studies on the Fauna of Suriname. Stud. Fauna Suri. and other Guy, The Hague, 2(4):1-103.

FINOT, A. , 1897. Catalogue des Orthoptères de l'Amérique Méridionale décrits jusqu'a ce jour, 1896. Actes Société Sciences du Chili, 7: 169-220.

FISK, F. W. \& WOLDA, H., 1979. Keys to the Cockroaches of Central Panama. Part I: Flying Species. Studies on Neotrop. Fauna Env., Amsterdam, 14:177-201.

GURNEY,A.B., KRAMER, J. P. \& STEYSKAL, G. C. 1964. Some techniques for the preparation, study and storage in microvials of insect genitalia. Ann. Entomol. Soc. Am., 57(2):240-242.

KIRBY, W. F., 1904. A Synonymic catalogue of Orthoptera. London. British Mus. Ed. I: X-1(61-205)-501.

McKITTRICK, F. A. 1964. Evolutionary studies of cockroaches. Mem. Cornell Univ. Agr. Exp. Station 389: 1-197.

ROTH, L. M. \& WILLIS, E. R. 1960. The biotic associations of cockroaches. Smiths. Misc. Coll. 141: 1-470.
VANSCHUYTBROECK, P., 1970. Catalogue des Blattariae conserves dans les collections Entomologique de l'Institut Royal des Sciences Naturelles de Belgique. Deuxieme partie: Nyctiboridae, Epilampridae \& Blattellidae. Bulletin Institut Royal des Sciences Naturelles de Belgique 46(20): 1-20.

Título: Espécie nova de ischnoptera burmeister, 1838 (blattaria: blattellidae: blattellinae) do estado de Goiás, Brasil, coletada em ninho de cupim.

Autores: Sonia Maria Lopes \& Edivar Heeren de Oliveira

Biota Neotropica, Vol. 5 (número 1): 2005

http://www.biotaneotropica.org.br/v $5 \mathrm{n} 1 / \mathrm{pt} /$ abstract?article+BN02405012005

Recebido: 04/10/2004

Revisado: 21/11/2004

Publicado: 01/01/2005

ISSN 1676-0603 